(c) American Dairy Science Association, 2003.

\title{
Assimilation of Cholesterol by Yeast Strains Isolated from Infant Feces and Feta Cheese
}

\author{
E. I. Psomas, ${ }^{\star}$ D. J. Fletouris,† E. Litopoulou-Tzanetaki, ${ }^{\star}$ and N. Tzanetakis ${ }^{\star}$ \\ *Laboratory of Food Microbiology and Hygiene, \\ Faculty of Agriculture and \\ †Laboratory of Milk Hygiene and Technology, \\ School of Veterinary Medicine, \\ Aristotle University of Thessaloniki, \\ GR-54124 Thessaloniki, Greece
}

\begin{abstract}
Eight yeast strains isolated from infant feces and the traditional Greek Feta cheese, selected for their probiotic properties, were tested along with a commercially available strain of Saccharomyces boulardii for their ability to remove cholesterol from a growth medium (yeast extract glucose peptone broth) supplemented with $0.3 \%$ Oxgall. The amount of cholesterol removed during $72 \mathrm{~h}$ of growth at $37^{\circ} \mathrm{C}$ revealed significant variations among the yeast strains examined. Two isolates from infant feces, namely Saccharomyces cerevisiae KK1 and Isaatchenkia orientalis KK5.Y.1 and one isolate from Feta cheese, namely $S$. cerevisiae 832 , along with the commercial strain $S$. boulardii, were able to remove cholesterol from the growth medium after $48 \mathrm{~h}$ of incubation at $37^{\circ} \mathrm{C}$. However, Saccharomyces strains proved to be able to remove cholesterol even after $24 \mathrm{~h}$ of growth at $37^{\circ} \mathrm{C}$. The cholesterol removed from the growth medium was not metabolically degraded but was rather assimilated into the yeast cells. The ability to assimilate cholesterol in vitro and to tolerate low $\mathrm{pH}$ levels, gastric juice, and bile indicate that $S$. cerevisiae 832 , and especially $S$. cerevisiae KK1 and I. orientalis KK5.Y.1 (being more bile and gastric juice tolerant because of their human origin) may be promising candidate strains for use as probiotics.
\end{abstract}

(Key words: yeast, probiotic, cholesterol, Feta cheese).

Abbreviation key: OD = optical density, YEGP = yeast extract glucose peptone.

\section{INTRODUCTION}

Public interest in cholesterol has increased owing to awareness and publicity of the relationship of serum

Received February 17, 2003.

Accepted July 7, 2003.

Corresponding author: E. I. Psomas; e-mail: akisp@agro.auth.gr. cholesterol to the risk of developing coronary heart disease and also of inducing colon cancer in addition to high dietary fat and low fiber (Reddy et al., 1977; Law et al., 1994). Any factor likely to raise serum cholesterol, such as dietary cholesterol, is generally considered to be unfavorable, although the role of dietary cholesterol in human health has not been yet fully elucidated.

The emerging public consensus that limited dietary cholesterol contributes to good health has resulted in a series of new guidelines for food labeling that includes specific regulations for cholesterol. In order to comply with these regulations, several methods have been developed to reduce cholesterol in foods by using various physical, chemical, and biological procedures (Larsen and Froning, 1981; Durkley, 1982; Micich, 1990; Lee et al., 1999). However, with the emergence of a more health-conscious society, the role of biological procedures (probiotic food products) has gained considerable attention from both producers and consumers. In this respect, the ingestion of probiotic microorganisms could prove to be a more natural way to reduce cholesterol uptake.

Several studies have indicated that consumption of certain lactic acid bacteria and bifidobacteria resulted in the reduction of serum cholesterol levels in humans (Homma, 1988; Gilliland and Walker, 1990) and animals (Toit et al., 1998; Taranto et al., 1998; 2000; Usman and Hosono, 2000). This hypocholesterolemic effect might be attributed either to the inhibition of the hydroxymethylglutaryl coenzyme A reductase (Boguslawski and Wrobel, 1974; Homma, 1988), or to the assimilation of cholesterol by lactic acid bacteria (Gilliland et al., 1985; Tahri et al., 1995; 1996; 1997; Taranto et al., 1998). In vitro experiments have revealed that during growth, lactic acid bacteria can remove cholesterol from laboratory media that have been supplemented with cholesterol micelles and bile salts (Brashears et al., 1998; Xanthopoulos et al., 1998; Pereira and Gibson, 2002; Kimoto et al., 2002). 
Relevant experiments concerning cholesterol assimilation by yeast strains grown in laboratory media under conditions typically found in the gastrointestinal tract of humans have not been yet reported. Nevertheless, several reports have indicated that during growth, yeasts can remove cholesterol from laboratory media supplemented with cholesterol micelles (Taylor and Parks, 1981; Todd Lorenz et al., 1986; Shinabarger et al., 1989; Ness et al., 1998). However, these reports are referred almost exclusively to Saccharomyces cerevisiae strains, grown mainly under optimum growth conditions.

The objective of this study was to evaluate the ability of eight yeast strains, isolated from traditional Greek Feta cheese and infant feces and exhibiting some probiotic properties (Psomas et al., 2001), to assimilate cholesterol in vitro under conditions typically found in the gastrointestinal tract of humans, and to compare them with the commercial probiotic strain Saccharomyces boulardii (Ultra Levure, Biocodex, France). The latter has been used successfully to prevent antibioticassociated and traveler's diarrhea, to treat recurrent Clostridium difficile disease, and to treat various other diarrheal illnesses (Surawicz et al., 1989; McFarland and Bernasconi, 1993; Elmer et al., 1996; Elmer, 2001; Czerucka and Rampal, 2002).

\section{MATERIALS AND METHODS}

\section{Source and Maintenance of Yeast Strains}

In this study, eight yeast strains obtained from the culture collection of the laboratory of Food Microbiology and Hygiene were used. Among them, the strains S. cerevisiae KK1, Isaatchenkia orientalis KK5.Y.1, Candida albicans KK2.1, and Candida parapsilosis KK6.P were isolated from infant feces, while the strains Kluyveromyces marxianus 630, Kluyveromyces lactis 570, Pichia farinosa 441, and S. cerevisiae 832 were isolated from the traditional Greek Feta cheese (Psomas et al., 2001). The strain S. boulardii, also used in this study, was isolated from the commercial yeast product Ultra Levure and characterized by molecular methods, namely RAPD-PCR fingerprinting and mtDNA restriction analysis (Psomas et al., 2001). The cultures were stored at $5^{\circ} \mathrm{C}$ and were subcultured at least three times prior to experimental use.

\section{Growth Media and Culture Conditions}

Yeast extract glucose peptone (YEGP) broth (2\% glucose, $0.5 \%$ yeast extract, $1 \%$ peptone) was used for subculturing yeast strains at $25^{\circ} \mathrm{C}$ for $24 \mathrm{~h}$. A YEGP agar $(0.5 \%$ glucose, $0.5 \%$ yeast extract, $1 \%$ peptone,
$1.8 \%$ agar) was used for maintaining the cultures. A YEGP broth was supplemented with $0.3 \%$ Oxgall (Difco Laboratories, Detroit, MI) and used to assess the ability of the yeast strains to assimilate cholesterol.

The yeast strains were activated overnight at $25^{\circ} \mathrm{C}$ by three subcultures in YEGP broth. The cultures obtained were inoculated (1\%) in tubes containing $12 \mathrm{ml}$ of YEGP broth supplemented with $0.3 \%$ Oxgall and $224.2 \mu \mathrm{g} / \mathrm{ml}$ of cholesterol (lipids cholesterol rich solution; Sigma Chemical Co., St. Louis, MO) and incubated at $37^{\circ} \mathrm{C}$ for 12 to $72 \mathrm{~h}$. Although the optimum incubation temperature of yeasts is 25 to $30^{\circ} \mathrm{C}$, all experiments were carried out at $37^{\circ} \mathrm{C}$ in order to simulate the conditions of the human gastrointestinal tract. After incubation, the cells were harvested by centrifugation $\left(12,000 \times g\right.$ for $15 \mathrm{~min}$ at $\left.2^{\circ} \mathrm{C}\right)$ and a small quantity $(1 \mathrm{ml})$ of the supernatant fluid was prepared for GC analysis. The pellet was resuspended in sterile distilled water $(12 \mathrm{ml})$ and a small quantity of this suspension ( $1 \mathrm{ml})$ was also prepared for gas chromatographic analysis.

\section{Measurement of Cholesterol Assimilation}

Cholesterol determination in liquid samples was carried out using the method developed by Fletouris et al. (1998) for the determination of cholesterol in milk and milk products. According to this method, an aliquot $(1 \mathrm{ml})$ of the sample and $5 \mathrm{ml}$ of methanolic $\mathrm{KOH}$ solution were added into a sample preparation tube. The tube was tightly capped and its content was vortex mixed for $15 \mathrm{~s}$. The tube was then transferred to a water bath set at $80^{\circ} \mathrm{C}$ and remained there for 15 min, removing the tube every 5 min for a quick 10 -s vortexing. After heating, the tube was cooled under tap water, $1 \mathrm{ml}$ of water and $5 \mathrm{ml}$ of hexane were added, and the contents were vortexed vigorously for $1 \mathrm{~min}$ to be further centrifuged for $1 \mathrm{~min}$ at $2000 \times \mathrm{g}$. An aliquot of the upper phase was transferred into the autosampler vial pending GC analysis.

Analysis was carried out on a capillary column GC system (model GC-15A; Shimadzu Corp., Kyoto, Japan), equipped with a flame ionization detector, an automatic sampler (model AOC-17), and a chromatography data system (model Class-VP). A fused silica capillary column $(15 \mathrm{~m} \times 0.32 \mathrm{~mm}$ i.d.), coated with SPB-1 with $1.0-\mu \mathrm{m}$-film thickness (Supelco Inc., Bellefonte, PA), was used in this study. Oven temperature was set at $285^{\circ} \mathrm{C}$, injection port temperature at $300^{\circ} \mathrm{C}$, and flame ionization detector temperature at $300^{\circ} \mathrm{C}$. The flow rates were $2 \mathrm{ml} / \mathrm{min}$ for helium, $30 \mathrm{ml} /$ min for hydrogen, and $300 \mathrm{ml} / \mathrm{min}$ for air. The injection volume was $1 \mu \mathrm{l}$ with a split ratio of $20: 1$. 
Table 1. Cholesterol assimilation by various yeast strains inoculated in YEGP broth, supplemented with Oxgall $(0.3 \%)$ and cholesterol $(224.2 \mu \mathrm{g} / \mathrm{ml})$ and incubated at $37^{\circ} \mathrm{C}$.

\begin{tabular}{lllll}
\hline & \multicolumn{4}{c}{ Cholesterol assimilation $(\%)^{1}$} \\
\cline { 2 - 5 } Strain & 12 h incubation & $24 \mathrm{~h}$ incubation & $48 \mathrm{~h}$ incubation & $72 \mathrm{~h}$ incubation \\
\hline Saccharomyces boulardii & $9.7^{\mathrm{d}}(1.8)$ & $86.7^{\mathrm{b}}(5.0)$ & $90.6^{\mathrm{b}}(3.8)$ & $93.2^{\mathrm{d}}(3.4)$ \\
Saccharomyces cerevisiae KK1 & $2.3^{\mathrm{b}}(0.8)$ & $97.7^{\mathrm{c}}(5.5)$ & $96.8^{\mathrm{b}}(6.0)$ & $95.7^{\mathrm{d}}(4.0)$ \\
Saccharomyces cerevisiae 832 & $4.5^{\mathrm{c}}(0.8)$ & $83.4^{\mathrm{b}}(6.8)$ & $90.4^{\mathrm{b}}(3.7)$ & $91.7^{\mathrm{d}}(2.1)$ \\
Isaatchenkia orientalis KK5.Y.1 & $0.0^{\mathrm{a}}$ & $0.0^{\mathrm{a}}$ & $88.1^{\mathrm{b}}(7.7)$ & $93.6^{\mathrm{d}}(4.9)$ \\
Candida albicans KK2.1 & $0.0^{\mathrm{a}}$ & $0.0^{\mathrm{a}}$ & $2.5^{\mathrm{a}}(1.4)$ & $5.4^{\mathrm{bc}}(1.2)$ \\
Candida parapsilosis KK6.P & $0.0^{\mathrm{a}}$ & $0.0^{\mathrm{a}}$ & $0.0^{\mathrm{a}}$ & $4.5^{\mathrm{ab}}(1.7)$ \\
Kluyveromyces marxianus 630 & $0.0^{\mathrm{a}}$ & $0.0^{\mathrm{a}}$ & $0.0^{\mathrm{a}}$ & $2.7^{\mathrm{a}}(0.8)$ \\
Kluyveromyces lactis 570 & $0.0^{\mathrm{a}}$ & $0.0^{\mathrm{a}}$ & $0.0^{\mathrm{a}}$ & $4.0^{\mathrm{ab}}(1.4)$ \\
Pichia farinosa 441 & $0.0^{\mathrm{a}}$ & $0.0^{\mathrm{a}}$ & $4.3^{\mathrm{a}}(1.2)$ & $7.9^{\mathrm{c}}(1.0)$ \\
\hline \multicolumn{2}{c}{ a,b,c,d Mean values in the same column with a letter in common do not differ significantly $(P>0.05)}$. \\
\multicolumn{1}{c}{${ }^{1}$ Mean of three replicates; values in parentheses represent standard deviations. }
\end{tabular}

For the determination of cholesterol in liquid samples, a seven-point calibration curve was generated by injecting $1 \mu \mathrm{l}$ from each working standard solution, plotting the recorded peak area versus the corresponding mass of the analyte injected, and computing the slope, intercept, and least squared fit of the standard curve. The data for the slope and the intercept of the calibration curve were used to compute the mass of the analyte in injected unknown sample extracts $(1 \mu \mathrm{l})$.

\section{Evaluation of Yeast Growth}

In order to determine the growth level needed for the yeast strains to uptake the greatest amount of the added cholesterol, the population of the yeast cells was evaluated at different incubation times. For this purpose, activated yeast strains were inoculated at a ratio of $1 \%$ in YEGP broth $(5 \mathrm{ml})$, supplemented with $0.3 \%$ Oxgall and $224.2 \mu \mathrm{g} / \mathrm{ml}$ cholesterol, and the turbidity of the cell suspension, expressed as optical density (OD) units recorded at $600 \mathrm{~nm}$, was measured during incubation at $37^{\circ} \mathrm{C}$ at 6 -h intervals using a spectrophotometer (Madigan et al., 2000).

\section{Resistance of Yeast Cells to Lysis}

The yeast strains were activated overnight at $25^{\circ} \mathrm{C}$ by three subcultures in YEGP broth. Cultures obtained were inoculated at a ratio of $1 \%$ in YEGP broth and in YEGP broth supplemented with $224.2 \mu \mathrm{g} / \mathrm{ml}$ cholesterol and $0.3 \%$ Oxgall. The inoculated media were incubated at $37^{\circ} \mathrm{C}$ for 12 to $72 \mathrm{~h}$. The yeast cells were harvested by centrifugation $(12,000 \times g$ for 15 $\min$ at $2^{\circ} \mathrm{C}$ ).

The cells were lysed via cell wall digestion (Andrighetto et al., 2000) with the lysing enzymes from Rhizoctonia solanii (Sigma Chemical Co.). The number of intact cells was counted by direct microscopic count (Vanderzant and Splittstoesser, 1990).
There was also an attempt made to lyse the cells by sonication. The cell suspension was transferred to a small beaker and was sonicated for $15 \mathrm{~min}$ in a sonic dismembrator (Fisher Scientific, Pittsburgh, PA) that was adjusted to the maximum output. The beaker containing the cell suspension was held in an ice-water bath during sonication to prevent it from heating up. The number of intact cells was counted by direct microscopic count.

\section{Statistical Analysis}

For the statistical analysis of the experimental data the SPSS statistical package (SPSS 10.0 for Windows, SPSS Ltd., Surrey, UK) was used. The normal distribution of the data concerning cholesterol assimilation was tested using the Shapiro-Wilk and Lilliefors tests, whereas the homogeneity of variances was tested using the Levene's test. Because of the nonnormal distribution of data and the heterogeneity of variances, cholesterol assimilation was finally evaluated by the nonparametric Kruskall-Wallis test, while differences between specific mean values were tested using the nonparametric Mann-Whitney U-test. Significance was declared at $P \leq 0.05$.

\section{RESULTS AND DISCUSSION}

The ability of eight yeast strains, isolated from traditional Greek Feta cheese and infant feces, and a commercial probiotic yeast strain to assimilate cholesterol from the YEGP broth supplemented with $0.3 \%$ Oxgall and $224.2 \mu \mathrm{g} / \mathrm{ml}$ cholesterol, is shown in Table 1 . The experimental results reveal a significant variation among the yeast strains examined on their ability to remove cholesterol in vitro after $12,24,48$, and $72 \mathrm{~h}$ of growth at $37^{\circ} \mathrm{C}(P \leq 0.05)$. The strains $S$. cerevisiae KK1 isolated from infant feces, $S$. cerevisiae 832 isolated from Feta cheese, and the commercial probiotic 
Table 2. Growth ${ }^{1}$ of various yeast strains in YEGP broth supplemented with Oxgall $(0.3 \%)$ and cholesterol $(224.2 \mu \mathrm{g} / \mathrm{ml})$ and incubated at $37^{\circ} \mathrm{C}$.

\begin{tabular}{lllll}
\hline Strain & $\mathrm{OD}_{600} / 12 \mathrm{~h}$ & $\mathrm{OD}_{600} / 24 \mathrm{~h}$ & $\mathrm{OD}_{600} / 48 \mathrm{~h}$ & $\mathrm{OD}_{600} / 72 \mathrm{~h}$ \\
\hline Saccharomyces boulardii & 0.216 & 0.740 & 1.180 & 1.415 \\
Saccharomyces cerevisiae KK1 & 0.204 & 0.684 & 0.940 & 1.175 \\
Saccharomyces cerevisiae 832 & 0.356 & 1.015 & 1.520 & 1.590 \\
Isaatchenkia orientalis KK5.Y.1 & 0.158 & 0.800 & 1.030 & 1.235 \\
Candida albicans KK2.1 & 0.174 & 0.370 & 0.392 & 0.420 \\
Candida parapsilosis KK6.P & 0.138 & 0.328 & 0.516 & 0.730 \\
Kluyveromyces marxianus 630 & 0.070 & 0.160 & 0.193 & 0.280 \\
Kluyveromyces lactis 570 & 0.092 & 0.133 & 0.220 & 0.369 \\
Pichia farinosa 441 & 0.124 & 0.416 & 0.845 & 1.048 \\
\hline
\end{tabular}

${ }^{1}$ The growth of each strain was determined by measuring the optical density (OD) of the culture at 600 $\mathrm{nm}$. All values are the means of three replicates.

strain S. boulardii were able to remove various amounts of cholesterol from YEGP broth when incubated for more than $12 \mathrm{~h}$ at $37^{\circ} \mathrm{C}$. Cholesterol removal, although almost negligible after $12 \mathrm{~h}$ of growth $(<9.7 \%)$, was excellent after $24 \mathrm{~h}(>83.4 \%)$ and $48 \mathrm{~h}$ $(>90.4 \%)$, achieving the highest value $(>91.7 \%)$ after $72 \mathrm{~h}$ of growth. The strain I. orientalis KK5.Y.1, isolated from infant feces, showed a similar behavior when incubated for more than $48 \mathrm{~h}$ at $37^{\circ} \mathrm{C}$. No statistically significant differences were found between the above-mentioned yeast strains and the commercial strain with regard to cholesterol removal $(P>0.05)$ after 48 and $72 \mathrm{~h}$ of growth at $37^{\circ} \mathrm{C}$. However, cholesterol removal by the strain $S$. cerevisiae KK1 was significantly higher than that of the commercial strain $(P \leq 0.05)$, during $24 \mathrm{~h}$ of growth. Removal of cholesterol by the other yeast strains examined was almost negligible after $72 \mathrm{~h}$ of growth at $37^{\circ} \mathrm{C}$ (Table 1).

From analogous experiments, which were conducted using lactic acid bacteria and bifidobacteria, it has been recognized for many years that these bacteria can remove cholesterol from growth media that have been supplemented with cholesterol micelles and bile salts (Tahri et al., 1995, 1996, 1997; Brashears et al., 1998; Pereira and Gibson, 2002; Kimoto et al., 2002). However, cholesterol removal by lactic acid bacteria and bifidobacteria was lower than that recorded in our study using I. orientalis KK5.Y.1 and Saccharomyces strains.

As regards the growth of the yeast strains in YEGP broth supplemented with Oxgall $(0.3 \%)$ and cholesterol $(224.2 \mu \mathrm{g} / \mathrm{ml})$, it was evaluated by measuring the turbidity of the cell suspension at $600 \mathrm{~nm}$, during incubation at $37^{\circ} \mathrm{C}$, using a spectrophotometer. The results presented in Table 2 show that three yeast strains, namely $C$. albicans KK2.1, $K$. marxianus 630 , and $K$. lactis 570, reached low OD values after $72 \mathrm{~h}$ of growth at $37^{\circ} \mathrm{C}$, which justifies the almost negligible cholesterol removal from the growth medium. All other six strains reached high OD values after $72 \mathrm{~h}$ of growth but only four of them, namely $S$. cerevisiae KK1, $S$. cerevisiae 832 , I. orientalis KK5.Y.1, and S. boulardii, were able to remove cholesterol from the growth medium (Table 1). These four strains revealed high OD values and excellent cholesterol removal $(>88.1 \%)$ after $48 \mathrm{~h}$ of growth (Tables 1 and 3). However, the two $S$. cerevisiae strains and the commercial strain $S$. boulardii proved to be able to remove cholesterol $\left(>83.4 \%\right.$ ) even after $24 \mathrm{~h}$ of growth at $37^{\circ} \mathrm{C}$. It is worth noticing that I. orientalis KK5.Y.1, although it reached a satisfactory OD value, could not remove cholesterol from YEGP broth after $24 \mathrm{~h}$ of incubation at $37^{\circ} \mathrm{C}$ (Tables 1 and 2). These data indicate that, although cholesterol removal is mainly dependent on the rate of yeast growth in YEGP broth, Saccharomyces strains remove cholesterol more rapidly than $I$. orientalis KK5.Y.1. These findings lend support to similar observations made by Gilliland and Walker (1990) using Lactobacillus acidophilus strains.

The failing of I. orientalis KK5.Y.1 to remove cholesterol during the first $24 \mathrm{~h}$ of growth suggested the presence of inhibition factors in the YEGP broth that prevent cholesterol removal. The supplementation of the YEGP broth with $0.3 \%$ Oxgall, along with the incubation temperature $\left(37^{\circ} \mathrm{C}\right)$, appeared to be significant inhibition factors since in the absence of Oxgall, cholesterol removal from the YEGP broth reached 93\% after $12 \mathrm{~h}$ of growth of $I$. orientalis KK5.Y.1 at $25^{\circ} \mathrm{C}$. Similar behavior was observed with the Saccharomyces strains, while the other yeast strains tested revealed significant increase of cholesterol removal even after $12 \mathrm{~h}$ of growth in YEGP broth at $25^{\circ} \mathrm{C}$. These findings agree with the results of several reports (Taylor and Parks, 1981; Todd Lorenz et al., 1986; Shinabarger et al., 1989; Ness et al., 1998) referring almost exclusively to $S$. cerevisiae strains that indicated that yeasts can remove cholesterol from laboratory media supplemented with cholesterol micelles, when cultured under optimum growth conditions. 
Table 3. Cholesterol assimilation ability and growth of yeast strains inoculated in YEGP broth supplemented with Oxgall $(0.3 \%)$ and cholesterol $(224.2 \mu \mathrm{g} / \mathrm{ml})$, and incubated for $48 \mathrm{~h}$ at $37^{\circ} \mathrm{C}$.

\begin{tabular}{|c|c|c|c|c|}
\hline \multirow[b]{2}{*}{ Strain } & \multicolumn{3}{|c|}{ Cholesterol concentration $(\mu \mathrm{g} / \mathrm{ml})^{1}$} & \multirow[b]{2}{*}{$\begin{array}{l}\text { Growth } \\
\left(\mathrm{OD}_{600}\right)\end{array}$} \\
\hline & $\begin{array}{l}\text { Supernatant } \\
\text { fluid }\end{array}$ & $\begin{array}{l}\text { Aqueous cells } \\
\text { suspension }^{2}\end{array}$ & $\begin{array}{l}\text { Digested cells } \\
\text { suspension }^{3}\end{array}$ & \\
\hline Control & $223.9(1.5)$ & & & \\
\hline Saccharomyces boulardii & 0.0 & 0.0 & $203.1(8.5)$ & 1.180 \\
\hline Saccharomyces cerevisiae KK1 & 0.0 & 0.0 & $216.9(13.6)$ & 0.940 \\
\hline Saccharomyces cerevisiae 832 & 0.0 & 0.0 & $202.7(8.3)$ & 1.520 \\
\hline Isaatchenkia orientalis KK5.Y.1 & $12.3(6.8)$ & 0.0 & $197.5(17.4)$ & 1.030 \\
\hline Candida albicans KK2.1 & $213.8(12.5)$ & 0.0 & $5.6(3.2)$ & 0.392 \\
\hline Candida parapsilosis KK6.P & $223.4(7.3)$ & 0.0 & 0.0 & 0.516 \\
\hline Kluyveromyces marxianus 630 & $223.5(10.3)$ & 0.0 & 0.0 & 0.193 \\
\hline Kluyveromyces lactis 570 & $220.6(4.8)$ & 0.0 & 0.0 & 0.220 \\
\hline Pichia fainosa 441 & $210.4(5.6)$ & 0.0 & $9.7(2.8)$ & 0.845 \\
\hline
\end{tabular}

The mechanism by which yeasts remove cholesterol from YEGP broth during growth was also investigated. The results from the GC analysis showed that the amount of cholesterol that was recovered in the resuspended yeast cells was always negligible, although in many cases no cholesterol was determined in the supernatant fluid (Table 3). These results suggest that cholesterol removal from YEGP broth was not related to coprecipitation with the bile salts but to uptake by the growing yeast cells. On the contrary, Klaver and Van der Meer (1993) and Brashears et al. (1998) have reported that cholesterol removal by some lactobacilli is only due to destabilization of the cholesterol micelles and coprecipitation of cholesterol with the deconjugated bile salts at $\mathrm{pH}$ values less than 6.0. The absence of cholesterol in the resuspended yeast cells, observed in our study, might be attributed either to its metabolic degradation by the cells or to the resistance of yeast cells to lysis under the saponification conditions used for sample preparation.

By enumerating intact yeast cells using direct microscopic count, it was found that yeast cells were resistant to the strong saponification conditions used for sample preparation. In an attempt made to lyse the cell walls by sonication, it was found that yeast cells that were grown in the medium containing both Oxgall and cholesterol were more resistant $(P \leq 0.05)$ to lysis by sonication than cells grown in the medium without them (Table 4). When yeast cells were grown in YEGP broth, great differences were observed among the strains tested with regard to their ability to withstand sonication for $15 \mathrm{~min}$. The results showed that the percentage of yeast cells lysed, ranged from 11 to $93 \%$. From the strains tested, C. albicans KK2.1 and $C$. parapsilosis KK6.P were the most sensitive (> 85\% lysis), while Saccharomyces strains were the most re- sistant $(<20 \%$ lysis). However, when yeast cells were grown in YEGP broth containing Oxgall and cholesterol, less than $20 \%$ of the cells were lysed during sonication for the same time period. These findings agree with the results of another study reporting great resistance to lysis by sonication of Lactobacillus acidophilus ATCC 43121 cells that were grown in the presence of cholesterol micelles and bile salts, suggesting a possible alteration of the cell wall or cell membrane (Noh et al., 1997). In our study, a high degree of cell wall lysis was achieved (> 90\%) when the lysing enzymes from Rhizoctonia solanii were used.

These findings suggest that the evidence of cholesterol assimilation would be its recovery in the resuspended yeast cells after digestion of the cell walls with the above-mentioned lysing enzymes. The experimental results presented in Table 3 indicate that the amounts of cholesterol recovered in the digested cells suspension were close to the theoretically expected. Thus, the cholesterol removed by the yeast strains

Table 4. Resistance to lysis by sonication of yeast cells grown in the presence and absence of Oxgall and cholesterol.

\begin{tabular}{lll}
\hline & \multicolumn{2}{c}{ Lysis of yeast cells $(\%)^{1}$} \\
\cline { 2 - 3 } & & $\begin{array}{l}\text { YEGP broth } \\
\text { with Oxgall } \\
\text { and cholesterol }\end{array}$ \\
Strain & YEGP broth & $<3$ \\
\hline Saccharomyces boulardii & 11 & $<3$ \\
Saccharomyces cerevisiae KK1 & 14 & $<3$ \\
Saccharomyces cerevisiae 832 & 20 & 7 \\
Isaatchenkia orientalis KK5.Y.1 & 34 & 19 \\
Candida albicans KK2.1 & 85 & 15 \\
Candida parapsilosis KK6.P & 93 & 6 \\
Kluyveromyces marxianus 630 & 30 & $<3$ \\
Kluyveromyces lactis 570 & 22 & $<3$ \\
Pichia farinosa 441 & 18 &
\end{tabular}

${ }^{1}$ All values are the means of three replicates. 
tested was not metabolically degraded. These results demonstrate that the assimilation of cholesterol into yeast cells was the only mechanism by which yeast strains removed cholesterol from the growth medium. Assimilation is also the possible mechanism to remove cholesterol from media by lactococcal strains (Kimoto et al., 2002), whereas cholesterol removal by bifidobacteria is due to both bacterial assimilation and precipitation (Tahri et al., 1995, 1996).

It is worth noticing that cholesterol assimilation by the tested yeast strains never reached $100 \%$, although in many cases it was not determined in the supernatant fluid at all (Tables 1 and 3 ). This might be attributed to the degree of cell wall lysis by the lysing enzymes since it never reached $100 \%$.

\section{CONCLUSIONS}

The results from the present study clearly indicate that the strains $S$. cerevisiae KK1 and $S$. cerevisiae 832 , along with $S$. boulardii, were able to assimilate cholesterol (>83.4\%) in vitro after $24 \mathrm{~h}$ of incubation at $37^{\circ} \mathrm{C}$. Moreover, the strain I. orientalis KK5.Y.1, isolated from infant feces, exhibited comparable to the above mentioned yeast strains ability to assimilate cholesterol but this ability was developed after $48 \mathrm{~h}$ of growth at $37^{\circ} \mathrm{C}$. Furthermore, the above mentioned yeast isolates could tolerate low $\mathrm{pH}$ levels, gastric juice and bile concentrations typically found in the gastrointestinal tract of humans (Psomas et al., 2001). These results indicate that $S$. cerevisiae 832 , and especially $S$. cerevisiae KK1 and I. orientalis KK5.Y.1 (being more bile and gastric juice tolerant because of their human origin) may be promising candidate strains for use as probiotics.

\section{REFERENCES}

Andrighetto, C., E. Psomas, N. Tzanetakis, G. Suzzi, and A. Lombardi. 2000. Randomly amplified polymorhic DNA (RAPD) PCR for the identification of yeasts isolated from dairy products. Lett. Appl. Microbiol. 30:5-9.

Boguslawski, W., and J. Wrobel. 1974. An inhibitor of sterol biosynthesis in cow's milk. Nature 247:210-211.

Brashears, M. M., S. E. Gilliland, and L. M. Buck. 1998. Bile salt deconjugation and cholesterol removal from media by Lactobacillus casei. J. Dairy Sci. 81:2103-2110.

Czerucka, D., and P. Rampal. 2002. Experimental effects of Saccharomyces boulardii on diarrheal pathogens. Microbes Infect. 4:733-739.

Durkley, W. L. 1982. Reducing fat in milk and dairy products by processing. J. Dairy Sci 65:454-458.

Elmer, G. W., C. M. Surawicz, and L. V. McFarland. 1996. Biotherapeutic agents. A neglected modality for the treatment and prevention of selected intestinal and vaginal infections. JAMA 275:870-876.

Elmer, G. W. 2001. Probiotics: "Living drugs". Am. J. Health Syst. Pharmacol. 58:1101-1109.

Fletouris, D. J., N. A. Botsoglou, I. E. Psomas, and A. I. Mantis. 1998. Rapid determination of cholesterol in milk and milk products by direct saponification and capillary gas chromatography. J. Dairy Sci. 81:2833-2840, 1998.

Gilliland, S. E., C. R. Nelson, and C. Maxwell. 1985. Assimilation of cholesterol by Lactobacillus acidophilus. Appl. Environ. Microbiol. 49:377-381.

Gilliland, S. E., and D. K. Walker. 1990. Factors to consider when selecting a culture of Lactobacillus acidophilus as a dietary adjunct to produce a hypocholesterolemic effect in humans. J. Dairy Sci. 73:905-911.

Homma, N. 1988. Bifidobacteria as a resistance factor in human beings. Bifidobacteria Microflora 7:35-43.

Kimoto, H., S. Ohmomo, and T. Okamoto. 2002. Cholesterol removal from media by Lactococci. J. Dairy Sci. 85:3182-3188.

Klaver, F. A. M., and Van der Meer. 1993. The assumed assimilation of cholesterol by lactobacilli and Bifidobacterium bifidum is due to their bile salt deconjugation activity. Appl. Environ. Microbiol. 59:1120-1124.

Larsen, J. E., and G. W. Froning. 1981. Extraction and processing of various components from egg yolk. Poult. Sci. 60:160-167.

Law, M. R., N. J. Wald, T. Wu, A. Hackshaw, and A. Bailey. 1994 Systematic underestimation of association between serum cholesterol concentration and ischaemic heart disease in observational studies: data from the BUPA study. Br. Med. J. 308:363-366.

Lee, D. K., J. Ahn, and H. S. Kwak. 1999. Cholesterol removal from homogenized milk with $\beta$-cyclodextrin. J. Dairy Sci. 82:23272330.

Madigan, M. T., J. M. Martinko, and J. Parker. 2000. Pages 143144 in Brock Biology of Microorganisms. 9th ed. Prentice Hall International, New Jersey.

McFarland, L. V., and P. Bernasconi. 1993. Saccharomyces boulardii: A review of an innovative biotherapeutic agent. Microb. Ecol. Health Dis. 6:157-171.

Micich, T. J. 1990. Behaviors of polymer supported digitonin with cholesterol in the absence and presence of butter oil. J. Agric. Food Chem. 38:1839-1843.

Ness, F., T. Achstetter, C. Duport, F. Karst, R. Spagnoli, and E. Degryse. 1998. Sterol uptake in Saccharomyces cerevisiae heme auxotrophic mutants is affected by ergosterol and oleate but not by palmitoleate or by sterol esterification. J. Bacteriol. 180:1913-1919.

Noh, D. O., S. H. Kim, and S. E. Gilliland. 1997. Incorporation of cholesterol into the cellular membrane of Lactobacillus acidiphilus ATCC 43121. J. Dairy Sci 80:3107-3113.

Pereira, D. I. A., and G. R. Gibson. 2002. Cholesterol assimilation by lactic acid bacteria and bifidobacteria isolated from the human gut. Appl. Environ. Microbiol. 68:4689-4693.

Psomas, E, C. Andrighetto, E. Litopoulou-Tzanetaki, A. Lombardi, and N. Tzanetakis. 2001. Some probiotic properties of yeast isolates from infant feces and Feta cheese. Int. J. Food Microbiol. 69:125-133.

Reddy, B. S., A. Mastromarini, and E. Wynder. 1977. Diet and metabolism: Large bowel cancer. Cancer 39:1815-1819.

Shinabarger, D. L., G. A. Keesler, and L. W. Parks. 1989. Regulation by heme of sterol uptake in Saccharomyces cerevisiae. Steroids 53:607-623.

Surawicz, C. M., G. W. Elmer, P. Speelman, L. V. McFarland, J. Chinn, and G. van Belle. 1989. Prevention of antibiotic-associated diarrhea by Saccharomyces boulardii: A prospective study. Gastroenterology 96:981-988.

Tahri, K., J. Crociani, J. Ballonque, and F. Schneider. 1995. Effects of three strains of bifidobacteria on cholesterol. Lett. Appl. Microbiol. 21:149-151.

Tahri, K., J. P. Grill, and F. Schneider. 1996. Bifidobacteria strain behavior toward cholesterol: Coprecipitation with bile salts and assimilation. Curr. Microbiol. 33:187-193.

Tahri, K., J. P. Grill, and F. Schneider. 1997. Involvement of trihydroxyconjugated bile salts in cholesterol assimilation by bifidobacteria. Curr. Microbiol. 34:79-84.

Taranto, M. P., M. Medici, G. Perdigon, A. P. Ruiz Holgado, and G. F. Valdez. 1998. Evidence for hypocholesterolemic effect of 
Lactobacillus reuteri in hypercholesterolemic mice. J. Dairy Sci. 81:2336-2340.

Taranto, M. P., M. Medici, G. Perdigon, A. P. Ruiz Holgado, and G. F. Valdez. 2000. Effect of Lactobacillus reuteri on the prevention of hypercholesterolemia in mice. J. Dairy Sci. 83:401-403.

Taylor, F. R., and L. W. Parks. 1981. An assessment of the specificity of sterol uptake and esterification in Saccharomyces cerevisiae. J. Biol. Chem. 256:13048-13054.

Todd Lorenz, R., R. J. Rodriguez, T. A. Lewis, and L. W. Parks. 1986. Characteristics of sterol uptake in Saccharomyces cerevisiae. J. Bacteriol. 167:981-985.

Toit, M., C. M. A. P. Franz, L. M. T. Dicks, U. Schillinger, P. Haberer, B. Warlies, F. Ahrens, and W. H. Holzapfel. 1998. Characterisa- tion and selection of probiotic lactobacilli for a preliminary minipig feeding trial and their effect on serum cholesterol levels, faeces $\mathrm{pH}$ and faeces moisture content. Int. J. Food Microbiol. 40:93-104.

Usman, and A. Hosono. 2000. Effect of administration of Lactobacillus gasseri on serum lipids and fecal steroids in hypercholesterolemic rats. J. Dairy Sci 83:1705-1711.

Vanderzant, C., and D. Splittstoesser, ed. 1990. Compendium of Methods for the Microbiological Examination of Foods. 3rd ed. Am. Publ. Health Assoc., Washington, DC.

Xanthopoulos, V., N. Tzanetakis, and E. Litopoulou- Tzanetaki. 1998. In vitro effect of Lactobacilli and Pediococci on cholesterol. Microbiol. Alim. Nutr. 16:199-203. 